\title{
İngiliz Whig Tarihçiliği ve Thomas Carlyle
}

Michael TALBOT*

1930'da komik ve satirik bir tarih kitabı olan 1066 ve Bütün Hepsi (1066 and All That) yayınlandı. Aslında, bu kitabın yazarları, W.C. Sellar ve R.J. Yeatman tarihçi değil, Punch dergisi (Karagöz'e benzer bir satirik dergisi) mizahçılarıydı. İngiliz okullarında öğretilen tarihsel anlatıları hiciv ettiler. Yabancı bir kültüre çevirmenin en zor kısımlarından biri mizahtır. Bu kitap İngiliz mizahının tipik bir örneğidir. Kitap, Britanya'nın Roma fethinden Birinci Dünya Savaşı'na kadar olan İngiliz tarihini anlatmaktadır. İngiliz Adaları'nın birleşmesi, zorbalığa karşı mücadele ve parlamentonun yükselişi ve İngiliz liberalizmi, imparatorluğu, ve kültürünün zaferinin birer hikayesini içerir. Bu anlatıma katkıda bulunan tarihî bir olay 'iyi bir şey' olarak tanımlandı. Kitabın son bölümü Birinci Dünya Savaşı'nın bitiminden sonra 'kötü bir şey' ile sonuçlanır. Paris Barış Konferansı'ndaki Amerikan Başkanı Wison'ın “On Dört Nokta Zaferi”nden dolayı Sellar ve Yeatman hicivsel olarak 'Amerika açıkça en büyük ulustu, ve tarih durdu' diyerek sona ermiştir.

1066 ve Bütün Hepsi genellikle Whig Tarihi adı verilen tarihçiliğin önemli bir eleştirisini sunmaktadır. 'Whig' 17. yüzyılın sonunda ve 18. yüzy1l süresince İngiliz siyasetine egemen olan liberal partinin adıdır. İngiliz Sivil Savaşlarında (1642-51) İngiltere, İskoçya ve İrlanda krallıkları, bir tarafta otokratik ve Katolik eğilimli kral I. Charles'ın destekçileri ile diğer tarafta Protestan dini ve hukukun üstünlügünü korumak isteyen Parlamento taraftarları arasında bölünmüştü. Kral savaşı kaybetmiş ve idam edilmişti. Cumhuriyet ilan edilmişti. Ancak Parlamentonun ordu generallerinden Oliver Cromwell tarafindan bir kral gibi yönetilmişti. Cromwell öldügünden sonra, Parlamento kralzadelerin sürgünden Londra'ya dönmesini istedi. Böylece 1660 'de II. Charles taç giymişti. Bu dönemde Whig veya Liberal Parti, kralın yetkisi karşında Parlamentonun egemenliği garantilemek, Protestanlığın her biçiminin uygulanmasını korumak ve Katoliklerin İngiliz siyasetine katılmına karşı çıkmak için bir gündeme ile gelmiştir. Dolayısıyla, Whigizm 17. ve 18. yüzyıllarda İngiliz siyasetinde önemli bir siyasi grup oluşturmuştur. Tory veya Muhafazakâr Parti, İngiltere Kilisesi'nin, arazi sahibi aristokrasinin ve eski asaletin geleneksel güçlerini temsil ederken; Whig Partisi, muhalif Protestanlar (İngiltere Kilisesinin bir parçası olmayan Protestanlar), tacirler ve yeni orta sinıflar tarafindan desteklendi.

\footnotetext{
*Yrd. Doç. Dr., Greenwich Üniversitesi, m.h.talbot@greenwich.ac.uk
} 
Whigçiler, siyasi ve ekonomik liberalizme, düşünce ve vicdan özgürlüğüne dayanıyorlardı. Britanya'nın dünyadaki rolünün özgürlük ve refahı desteklemekle olacağına inanmışlardı. Bu inanç dönem ve sonraki dönemlerin tarih yazıcılığına yansımıştır. İngiliz tarihçiliğine Whig dünya görüşünün merkeziyetçiliğini modelleyen tarihçilerden biri Thomas Babington Macaulay'dı. Macaulay, 1830'lu ve 1840'lı yıllarda liberal hükümetlerde kıdemli pozisyonlarda görev yapan bir politikacıydı. Hindistan'daki İngiliz kolonilerinde görevliyken, Avrupalı bilgi ve kültürün Hintlilere kıyasla üstünlügünü iddia etmiştir. Ona göre Hintliler, ancak İngiliz kültürünü benimserlerse uygarlaşabilirlerdi. Bunun sonucunda yerleşik Hintçe ve Farsça yerine İngilizce eğitim ve yönetim dilini olarak yaygınlaşmıştır. İngiliz kültürel ve politik ilerlemesine ilişkin bu fikirler, tarihyazımında da karşılığını buldu.

Macaulay 1820 'lerde ve 1830 'lerde tarih ve tarihyazımı üzerinde bir dizi makale yayınladı. 1828'de yayınlanan makalelerden biri, şair ve edebiyat bilimcisi Henry Neele'in Tarihin Romansl: Ingiltere (The Romance of History: England) adlı bir kitabın gözden geçirilmesiydi. Bu kitap halk hikayeleri, şiirler ve mitler aracılığıyla İngiliz tarihinin hikayesini anlatmıştır. Buna göre drama ve romans, gerçeklerden daha önemliydi. Macaulay için bu eser, tarihçilik zanaatkârını yansıtmak için bir fırsat sağladı:

Mükemmel tarihçi, onun eserinde bir dönemin karakteri ve ruhunu minyatürde sergileyen tarihçidir. Kanıtlarla destekleyebiliyorsa, O yalnızca gerçekleri ilişkilendirir ve alıntıları teklif verir. Fakat akılcı seçim, reddetme ve düzenleme yoluyla, kurgu tarafindan gasp edilen mekanları gerçeğe dönüştürür. ${ }^{1}$

$\mathrm{Bu}$ demektir ki, tarih yazarlığı gerçekleri kullanmalıydı, ancak aynı zamanda okuyucuya ilham verecek bir şekilde olmalıydı. Tarihte etkileyici bir anlatı olmalıdır. Macaulay bu anlatının ayrıca siyaset bilimini desteklemesi gerektiğini savunmuştur: 'Bu nedenle, ulusların iç tarihi hakkında samimi bir bilgi, politik olayların önceden kestirilebilmsi için kesinlikle gereklidir' şeklinde yazmıştır. ${ }^{2}$ Macaulay, bu teoriyi 1849'da yayınlanan II. James'in Tahta Çıkmasından Sonra Ingiltere Tarihi (The History of England from the Accession of James the Second) kitabında uygulamaya koymuştur.

\footnotetext{
${ }^{1}$ Thomas Babginton Macaulay, 'History Review: The Romance of History. England. By Henry Neele. London, 1828', The Edinburgh Review 13:47 (1828), 331-367. 'The perfect historian is he in whose work the character and spirit of an age is exhibited in miniature. He relates no fact, he attributes no expression to his characters, which is not authenticated by sufficient testimony. But by judicious selection, rejection, and arrangement, he gives to truth those attractions which have been usurped by fiction.' s.364.

${ }^{2}$ Macaulay, 'History Review'. 'An intimate knowledge of the domestic history of nations is therefore absolutely necessary to the prognosis of political events.' s.367.
} 
Bu kitap, II. James ve III. William'ın hükümetlerini incelemektedir. Yayınlandığında İngiliz İç Savaşı yaşanmaktaydı. 1685'te II. James tahta gelmiş, ama Katolik bir kral olduğundan Britanya'da çok kişiyi endişelenmişti. Babası, I. Charles gibi bir tiran olarak görülmüştü. Parlamentodaki muhalefette olan Whig Partisi, Avrupa'daki en güçlü Protestan kral Hollanda hükümdar Oranj'1ı William ile gizli görüşmelere başlamıştı. 1688 yılında Hollanda kralı William, James karşıtlarının daveti üzerine İngiltere'yi ordusu ile işgal etmişti. James, İrlanda'ya kaçmış, destekçileri İskoçya ve İrlanda'da savaşa devam etmesine rağmen 1690'da Fransa'da sürgünde yaşamak üzere ayrılmıştı. Hollanda kralı William, James'in kızı Mary ile evlenmişti ve birlikte eşit kral ve kraliçe olarak hüküm sürmüştü. Muhteşem Devrim (the Glorious Revolution) adı verilen bu olay sonucunda, İngiltere kralının Katolikliği ve Katoliklerin parlamento üyeliği yasaklanmıștır. Bu yeni bir yasa olan Haklar Bildirgesiyle (the Bill of Rights) kralın gücü kısıtlanmış ve Parlamentonun üstünlüğü ilan edilmiştir.

Macaulay, belirli bir nedenle İngiliz tarihindeki bu dönemi yazmayı seçmiştir. Otokratik ve Katolik II. James'in devrilmesini, Protestanlık ve Parlamentonun zaferi olarak İngilere'nin özel bir ilerleme yolunda olduğu şeklinde işlemiştir. Bu ilerlemeyle, Britanya'nın dünyada en özel ve en gelişmiş ulus olduğunu savunmuştur. Aşağıdaki alıntı, kitabın tanitımindandir:

$\mathrm{Bu}$ damalı tarihin genel etkisi, tüm dindar zihinlerde şükran ve tüm yurtseverlerin kalbinde umut duygusunu uyandırmak olacaktır. Aslında, son yüz altmış yıllık ülkemizin tarihi, fiziksel, ahlakî, ve entelektüel gelişimin tarihidir. Yalnızca hayal gücü olanlar, kendi çağlarının altın çağlarla karşılaştırıldıklarında yozlaşma ve çöküşten söz edebilirler. Ama gerçekten tarihlerini bilen hiç kimse böyle suratsız ve kasvetli bir görüşe katılmaz. ${ }^{3}$

$\mathrm{Bu}$ aslında Whig tarihinin klasik bir tanımıdır. Bu tarih düz bir çizgide gelişir. Bazen normal akışından sapabilirse de tarih cehaletten aydınlanmaya, tiranlıktan özgürlüğe ve yoksulluktan zenginliğe kadar bir yolu tarif eder. Macaulay ve diğerleri için Britanya bu yolda büyük mesafe kat eden ilk ulustur. Dolayısıyla, Whig tarihi yalnızca dünyada ilerlemenin tarihi

${ }^{3}$ Thomas Babington Macaulay, The History of England from the Accession of James II (London: Longman, 1849), c.1. 'The general effect of this chequered narrative will be to excite thankfulness in all religious minds, and hope in the breasts of all patriots. For the history of our country during the last hundred and sixty years is eminently the history of physical, of moral, and of intellectual improvement. Those who compare the age on which their lot has fallen with a golden age which exists only in their imagination may talk of degeneracy and decay: but no man who is correctly informed as to the past will be disposed to take a morose or desponding view of the present.' s.3. 
değil, aynı zamanda Britanya'nın siyasi sistemini, ticaret üstünlüğünü ve dünyaya imparatorluğunu ihraç eden bir tarihtir. Bu tarihyazımı 19. ve 20. yüzyıllarda İngiliz emperyalizminin ve sömürgeciliğin gelişmesini destekledi. İngiliz siyasi, ekonomik ve ırksal üstünlük hissini teşvik etti. Whig tarihinin mirası bugüne kadar geldi.

\section{Thomas Carlyle ve Büyük Adam Tarihi}

Whig tarihinin metodolojisi teleolojiktir. Demek ki Whig tarihinin anlatı yolculuğu şu andan itibaren başlar ve geçmişten bugüne doğrudan bir yolculuğu gösteren noktalar arar. Günümüz, geçmişin yorumlanmasını belirlemektir. Dahası, geçmişin yolu bir demiryolu gibi sabittir. Trenler demiryolu raylarında dolaşmak zorundadırlar. Benzer şekilde, Whig tarihçileri Britanya'nın özgürlük ve refaha doğru sabit bir yolculukta olduğuna inanıyorlardı. Fakat sabit raylı bir tren bile bir makinist gerektirir. İngiliz tarih yazıcılığında çok önemli bir tarihçi olan Thomas Carlyle, geçmişin de büyük adamların, tarihin anlatımına rehberlik etmesini sağlamaları gerektiğini teorileştirdi. Bu Tarihin Büyük Adamları (Great Man History) 19. yüzyıl tarihyazımı ve felsefesinde çok etkiliydi.

Aslında İngiliz tarihinde birçok büyük entelektüel İngiliz değil, İskoçyalıydı. Thomas Carlyle da İskoçyalı bir yazar, filozof ve tarihçiydi. Carlyle, 1795'de Batı İskoçya'nın kırsal alanı olan Dumfriesshire'de doğdu. Çok iyi bir eğitim aldı. Endinburgh Üniversitesi'nden mezun olduktan sonra öğretmen oldu. Birkaç y1ldan sonra üniversiteye döndü. Alman romantizmiyle, özellikle de Johann Gottleib Fichte'nin eserleriyle ilgilendi. Fichte'nin felsefesi Immanuel Kant'ın felsefesine verilen tepki idi. Fichte, bilginin, fikirlerin ve deneyimin egonun ürünü olduğunu savunmuştu. Bunun Carlyle'ın düşüncesi için doğuracağ sonuçlar, soyut tecrübeyi şekillendirmede bireyin önemidir. Birey dünyada düzen ve anlam sağliyordu.

Carlyle'nın tarihyazımında bireylerin merkezliliği iki büyük tarihi çalışmasında gözler önüne serilir. İlki, Fransız Devrimi: Bir Tarih (The French Revolution: A History) 1837'de yayındı. Olağanüstü bir tarih metnidir. Kitap, dramatik yazım, eski Yunan ve Roma'ya ima, birinci şahıs anlatıları ve ayrıntılı açıklamalar karışımıdır. Tercüme ederek güçlü anlatım güzelliklerini korumak imkansızdır. Carlyle, XVI. Louis egemenliğinin başlangıcından “Terör Dönemi” sonuna kadar Fransız Devrimi tarihini titizlikle araştırmıştı. Bu kitap sadece bir dönemin tarihi değil, tarihin felsefesi de yapmaktadır. Fransız Devriminin farklı süreçlerini görmüş, ekonomik ve siyasi nedenleri açıklamıştır. Dönemin şiddet ve kaosu hakkında bilgi vermeye çalışmıştır. 'Her şey Devrimde' diye yazdı. Bu nedenle Fransız Devrimi itici güçleri nelerdi: 
Her yeni dönemeçte yeni bir cevap isteyen başka bir soru şudur: Fransız İhtilali özel olarak nerededir? 'Kral sarayında, kralın veya kraliçenin yönetimlerin, kötui muamelenin, hiziplerin, ahmaklıkların ve sıkıntıların' bir kısımını cevaplar: kimini cevaplamadığımız ise 'Ulusal Mecliste,' büyük ve çeşitli bir kalabalık cevap verir. Dolayısıyla kendilerini gazetecinin koltuğuna oturtuyorlar ve buradan meclis içinde gözüken ilanlar, kanunlar, raporlar, mantıksal paragraflar, ve belâgatlı konuşmalar ve meclis dışındaki duyulabilir kargaşalar ve kargaşa söylentilerini kaydediyorlar, bunları da yayınladıkları birçok cilde yazıyorlar. Sonra da kitaplarını 'Fransız Devrimi Tarihi' olarak adlandırıyorlar. Birçok gazetenin yaptığı, resmi rapor, ve parlamento kayıtlarını kullanarak yayınlamayı yapmak çok kolay ama faydasız olurdu. Ulusal Meclis (şu anda Kurucu Meclis) kendi yolunda gidiyor; Anayasa hazırlanıyor, ancak Fransız Devrimi de yolunda gidiyor. Genel olarak, Fransız Devrimi palavrasının her şiddet içerikli konuşan ve düşünenlerinin kalbinde ve kafasında olduğunu söyleyemez miyiz? Onlar yirmibeş milyon adamın nasıl karmaşı kombinasyonda, eylemlerle ve karşı eylemlerle olaylar üretebileceğini, "hangi olay en önemli" ve "olayın analiz edilmesi için iyi perspektif nedir" soruları bunu anlamak için bir problem olarak durmaktadır. $^{4}$

Bu problemin çözümü ne olabilir? Tarih, milyonlarca insanın eylem ve düşüncelerinin bir ürünü ise açık bir anlatıyı algılamak zordur. Carlyle'in çözümü, 'kahraman' olarak adlandırdığı şeyi tanımlamaktır.

Fransız Devrimi: Bir Tarih'te bulunan kahramanlık anlatı bir örneği 28 Şubat 1791'de 'Hançerler Günü'nün açılmasıdır. Paris halkı, kral XVI. Louis'in Paris'i terk etmeye ve sürgüne kaçmaya çalışacağından endişelenmişti. Halk Tuileries Sarayı ile Chateau de Vincennes arasında gizli bir tünel olduğuna inanmış ve kralın kaçmak için burayı kullanacağını düşünmüştü. Bu nedenle, şehrin fakir banliyölerinden bir kalabalık kaleyi yok

\footnotetext{
${ }^{4}$ Thomas Carlyle, The French Revolution: A History (London: James Fraser, 1837). c.1. 'Another question which at every new turn will rise on us, requiring ever new reply is this: Where the French Revolution specially is? In the King's Palace, in his Majesty's or her Majesty's managements, and maltreatments, cabals, imbecilities and woes, answer some few: - whom we do not answer. In the National Assembly, answer a large mixed multitude: who accordingly seat themselves in the Reporter's Chair; and therefrom noting what Proclamations, Acts, Reports, passages of logic-fence, bursts of parliamentary eloquence seem notable within doors, and what tumults and rumours of tumult become audible from without, - produce volume on volume; and, naming it History of the French Revolution, contentedly publish the same. To do the like, to almost any extent, with so many Filed Newspapers, Choix des Rapports, Histoires Parlementaires as there are, amounting to many horseloads, were easy for us. Easy but unprofitable. The National Assembly, named now Constituent Assembly, goes its course; making the Constitution; but the French Revolution also goes its course. In general, may we not say that the French Revolution lies in the heart and head of every violent-speaking, of every violent-thinking French Man? How the Twenty-five Millions of such, in their perplexed combination, acting and counter-acting may give birth to events; which event successively is the cardinal one; and from what point of vision it may best be surveyed: this is a problem.' s.298-299.
} 
etmek için silahlarla Chateau de Vincennes'e yürümüştü. Aynı zamanda, kalabalığın kralı öldüreceğinden korktuğundan, asilzadelerin yüzlercesi, onu korumak için Tuileries Saray'a gitmişti. Bütün asilzadeler hançerlerle silahlandırıldığı için günün adı Hançerler Günü oldu. Hem kalabalık hem de asilzadeler çok şiddetli davrandıkları için çok tehlikeli anlar yaşandı. Carlyle tarihine göre, büyük General Lafayette'in girişimleriyle kaostan kaçınıldı. Lafayette, Vincennes’teki kalabalığı sakinleşdi ve Tuileries’teki asilzadeleri silahsızlandı. Carlyle, yönlendirmesi ve girişimleriyle, devrimin amaçlarının kargaşaya dönüşmediği için Lafayette’i tarihin yükünü taşıyan 'iki dünyalı kahraman' olarak adlandırmıştır.

Carlyle'in Fransız Devrimi: Bir Tarihi araştırması en önemli eserlerinden biridir. Carlyle'in olayları şekillendiren büyük adamlara verdiği önemle Alman romantizmi üzerine yaptığı çalışmayı bir tür Whig tarihçiliği ile birleştirdi. Kitabın başında, ünlü Alman şair Goethe'nin bir şiirini aktardı:

Bu ulusa örs ve hükümdara çekiç karşılaştırdım;

Aşağıda halk, ortada kavisli olan bir metal levha gibidir.

Metale vay! Rastgele darbeler metale keyfi olarak vurursa,

Bitmiş ibrik asla ortaya çıkmaz. ${ }^{5}$

Carlyle gibi tarihçiler için tarihin bir amacı vardı. Lâkin bu amaç, ancak büyük adamlar tarafından gerçekleştirilebilir. Goethe'nin şiirinde açıklandığı gibi, sadece demirci metal levhadan bir ibrik oluşturabilir. Büyük adam ya da kahraman, Carlyle'in tarih felsefesinin merkezidir. $\mathrm{Bu}$ onun ikinci büyük tarih çalışmasında, Kahramanlar, Kahraman-İbadet, ve Tarihte Kahramanlık Hakkında ${ }^{6}$ gösterilmiştir. Kitap 1840 yıllında yayınlandı ve Carlyle'in teorilerini anlattığ 1 bir dizi dersin bir ürünüdür. Altı ders, altı özel konu ve örnek etrafında yayınland1:

- $\quad$ İlahi olarak kahraman: Odin, paganizm, ve İskandav mitolojisi

- $\quad$ Peygamber olarak kahraman: Hz Muhammad ve İslam

- S S Sair olarak kahraman: Dante ve Shakespeare

- $\quad$ Rahip olarak kahraman: Luther ve Reformasyon, Knox ve Püritenlik

- $\quad$ Edebiyatçı olarak kahraman: Johnson, Rousseau ve Burns

- $\quad$ Kral olarak kahraman: Cromwell, Napoleon, ve modern devrimcilik

\footnotetext{
${ }^{5}$ Carlyle, French Revolution, c.1. 'Diesem Ambos vergleich ich das Land, den Hammer dem Herrscher, / Und dem Volke das Blech, das in der Mitte sich krümmt. / Wehe dem armen Blech! Wenn nur willkürliche Schläge / Ungewiss treffen und nie fertig der Kessel erscheint.'

${ }^{6}$ Kitap, Türkiye'de Kahramanlar adı ile yayınlandı.
} 
$\mathrm{Bu}$, Carlyle'in evrensel bir tarih dediği bir tarihtir. İlk dersde, 'İlahi olarak kahraman'ın net bir tanımını yaptı:

Evrensel tarih, yani insanlığın bu dünyada gerçekleştirdiği şeylerin tarihi temelde burada çalısan büyük adamların tarihidir. Bu büyük adamlar, insanların liderleriydi. Genel popülasyon ne yapmak isterse ya da elde etmek isterse, bu büyük adamlar model, kalıp yapımcısı, ve yaratıcıydı. Dünyada elde edilen her şey dünyaya gönderilen büyük adamların pratikte gerçekleşmesi ve düşüncelerinin somutlaşması sonucudur. Tüm dünya tarihinin ruhunun bu adamların tarihi olduğunu söylemek doğrudur. $^{7}$

$\mathrm{Bu}$ önemli paragraf, Carlyle'in düşüncesinin karmaşıklığını göstermektedir. Dünyadaki ilerleme, büyük adamların yönlendirmesi yoluyla sağlanırken, aynı zamanda yalnızca halkın eylemleri yoluyla başarılabilir. Bu, Carlyle'in 'Peygamber olarak kahraman' hakkında dersini önceleyerek daha ayrıntılı olarak düşünülebilir. Zamanın pek çok Avrupalı yazarının aksine, Carlyle, Muhammed hakkında olumlu bir yazı yazdı. İslam'a inanmasa da o, Kuran ve Muhammed'in gerçek bir samimiyet sergilediğini düşünüyordu. Bu sebepten "Muhammed'i gösterişçilikten uzak, tamamen özgür olduğunu için seviyorum" diye yazmıştı. ${ }^{8}$ Tarihsel bir perspektiften bakıldığında, Carlyle iki ana nedenden dolayı Muhammed'i analiz etmeyi seçti. Birincisi, Muhammed'i daha önceki putperest toplumlarda bir gelişme olarak yarattı̆g dinin ve toplumun şeklini görmüştü. Bu ilerleme, İslam'ın dünyadaki büyük başarısını açıklıyordu. Araplar çöl göçebeğinden büyük fethedicilere evrilmişti; 'Onlara inanabilecekleri bir mesajla bir kahraman peygamber gönderildi; sonuç olarak, fark edilmeyenleri dünyada fark edilenler oluştu ve mütevazileri dünyada güçlüler oluştu.'9

Whig tarihinde gördüğümüz ilerleme fikrinin önemi, Carlyle'in tarih hikayesinde görülüyor. Tanrılar ve peygamberler ile antik çağ olmuştur. Bundan sonra o antik çağı yerine şairler ve reformcuların bilimsel bilgi çağına geçilmiştir. Ardından edebiyatçiler ve komutanların aydınlanma ve siyasi devrim çağına gelmiştir. Bu nedenle, Carlyle'in tarihinde Muhammed ilerleme yolunda önemli bir aşamayı temsil etmiş, ama fikirleri ve uygulamaları bir yana yerinde alınmıştır.

\footnotetext{
7 Thomas Carlyle, On Heroes, Hero-Worship, and the Heroic in History (London: Chapman \& Hall, 1840). 'Universal history, the history of what man has accomplished in this world, is at bottom the History of the Great Men who have worked here. They were the leaders of men, these great ones; the modellers, patterns, and in a wide sense creators, of whatsoever the general mass of men contrived to do or to attain; all things that we see standing accomplished in the world are properly the outer material result, the practical realisation and embodiment, of Thoughts that dwelt in the Great Men sent into the world: the soul of the whole world's history, it may justly be considered, were the history of these.' s.3.

${ }^{8}$ Carlyle, On Heroes, s.83.

${ }^{9}$ Carlyle, On Heroes, s.90.
} 
Carlyle'in Muhammed'i analiz etmeyi seçmesinin ikinci nedeni, tarihin mekaniğini açıklamak istemesidir. Meşhur Arap tarihçi İbn-i Haldun, Mukaddime adlı kitabında bir tarihin devreviliğini (döngüelliğini) tarif etmişti. Şehirli bir toplum, güçlü bir göçebe toplum tarafindan fethedilir; göçebe toplum yerleşir; şehirleştikçe bu toplum da gücü kaybeder ve zayıflarlar ve güçlü başka bir göçebe toplum tarafından fethedilirler. Carlyle, tarih boyunca benzer bir desen görmüş, ancak onun için tarih düz bir çizgiydi, döngüsel değildi. Bir toplum öldüğünde, yeni bir toplumun onun yerini alması gerekir. Böylece, büyük adamlar veya kahramanlar eski dönemden yeniçağına geçiş sürecini yönlendirmesine rağmen, tarih sadece ileriye doğru ilerleyebilir. Muhammed'in başarısı hakkında yazarken, Carlyle ' $\mathrm{Bu}$ adam tam da dünyanın büyük ve derin yasaya katıldıktan sonra haklı ve yenilmez, erdemli ve belli bir fetih yolundadır' demişti. ${ }^{10}$ Carlyle için Muhammed başarılıydı, çünkü cehaleti yerinden etti, bilgiye değer verdi.

\section{Sonuç}

Carlyle'in kahramanlar üzerine son dersinde, onun zamanının devrimlerindeki büyük adamların rolüne değindi. "Her ne kadar son kahramanlarımız devrimci adamlar olarak çalışmış olsalar da yine de her büyük ve içten bu adamlar düzenliğin bir destekçisidir." ${ }^{11}$ Her tarihçi onun zamanının bir ürünüdür. Bir kişi istikrarsızlık veya hızlı değişim zamanlarında yaşarsa, onları anlamak için bir zorunluluk vardır. Hem Macaulay hem de Carlyle 19. yüzyılda yaşan siyasi devrimler vardı ve kentleşme ve sanayileşme gibi önemli ekonomik ve sosyal değişiklikler gibi büyük gelişmeleri yaşadılar. Bu iki tarihçi, "şimdi”yi anlamak için geçmişe baktılar. Macaulay, Britanya'nın diğer uluslara kıyasla güç ve istikrarını gördü. 17. yüzyılın politik devrimleriyle bu durumu açıkladı. Whig tarihi bir ilerleme hikayesi olarak Britanya’ya öncülük etti.

Carlyle, tarihi farklı bir şekilde anlatmıştır. O da tarihin ilerlemeye yönelik öyküsüne baktı, ama kahramanların rehberlik etmesinin önemini vurguladı. Fransız Devrimi gibi kaotik olayların yeni toplumlar üretme biçimini anlamaya çalıştı. Bunun cevabı akıllıca bir rehberlik ile kaçınılmaz ilerlemenin birleşimi idi. Günümüzde birçok tarih kitabı, büyük adamlar ve kahramanlar üzerinde yoğunlaşmaya devam ediyor. Bu yaklaşımda toplumların ve kültürlerin tarihleri tek bir adamın eylemlerine indirgenir; halkın mücadeleleri ve zaferleri, tek bir kahramanın işlerine atfedilir.

\footnotetext{
${ }^{10}$ Carlyle, On Heroes, s.67.

${ }^{11}$ Carlyle, On Heroes, s. 241.
} 
Carlyle'in çalışmaları ve araştırmaları, 19. yüzyılda İngiltere ve İngiliz toplumu anlamada çok önemlidir. Lâkin Carlyle'in fikirleri 20. yüzyılda derin etkilere ulaştı. 20. yüzyıl, büyük devrimler ve değişimler yüzyılıydı. Aynı zamanda, iradesinin gücü ile tarihi değiştirmek isteyen güçlü adamların bir yüzyılıydı. Belki Carlyle hayatta olsaydı, Hitler ya da Mussolini’yi büyük adamlarından biri olarak görürdü. Çünkü ilerleme görelidir. Mutlak ilerleme fikri ve yüce kahramanın varlığı, iktidarı toplumdan kaldırır. Carlyle demokrasi ya da halkın gücü ile ilgilenmedi; o tarih büyük adamlar tarafından yönetilen sabit bir yoldan gittiğine inand1. Sonraki gelişen tarihyazımları bu teoriye meydan okuyor ve bugün tarihçiler tarihi kendi şartlarıyla anlamaya çalışıyorlar. 


\section{Thomas Carlyle, Kahramanlar, Kahraman-İbadet, ve Tarihte Kahramanlı Hakkında} (1840). Ders 6: "Kral Olarak Kahraman: Cromwell, Napoleon ve Modern Devrimcilik"

Krallık denilen son kahramanlık biçimini inceleyelim. İnsanlar üzerinde bir komutan, Büyük adamların en önemlileri olarak görülüyor. İrademizi kralın iradesine tabi tutuyoruz ve sadakatle kendimizi teslim ederken, refahımızı buluyoruz. O, kahramanlığın, bir rahip veya bir öğretmen ise çeşitli şekillerinin en büyüğüdür. Bir insanda hayal edebileceğimiz dünyevi veya manevi onur ne olursa olsun, kralın içinde somutlaşır. O bizim üzerimizde komutan edecek, o sürekli olarak bize öğretecek, o da her gün ve her saatte ne yapacağımızı söyleyecek. O’na Latince ve Fransızca 'düzenleyici' anlamına gelen 'rex' ve 'roi' denir. Daha iyi olarak, ona İngilizce ve Almanca 'kral' anlamına gelen 'king' ve 'Könning' denir, kelimenin tam anlamıyla "yetenekli insan" anlamına gelir.

$\mathrm{Bu}$ konularda bir takım derin ve zor sorular ortaya çıkmaktadır. Şimdilik onlar hakkında konuşmaya ara vereceğim. Edmund Burke, jürinin adil yargılanmasının hükümetin ruhu olduğunu ve her yasa, yönetim, parlamento tartışmasının ve diğer her şeyin, oniki tarafsız adamdan bir jüri oluşturmanın mahkemede çıkarmak için var olduğunu savunmuştu. Daha mantıklı bir biçimde savundum ki daha iyi ya da kötü olarak için, bu dünyadaki tüm toplumsal eylemler, kralımızı ya da yetenekli adamı bulmayı amaçlamaktadır. Kendisine bize rehberlik etme firsatı bulabilmek için onur, ibadet, kraliyet, şövalyelik ve sair ile yetenek sembolleri verilecektir. Seçim konuşmaları, parlamento konuşmaları, reform yasaları ve Fransız devrimleri bu gerçeğe ve başka hiçbir şeye, yönelik olarak çalışmaktadır. Herhangi bir ülkede en yetenekli insanı bulun, onu üstün makama yükseltin ve ona sadakat gösterin. Dolayısıyla, o ülke mükemmel bir hükümete sahip olacaktır. Hiçbir oy sandığı, parlamento sözü, oy kullanma, anayasa inşaatı ya da başka herhangi bir sistem bunu geliştiremez. Mükemmel bir devlet olacak; kusursuz bir ülke olacak. En yetenekli adam, en gerçek, en yüce, en adaletli ve asil adam olarak, bize en bilgece ve en uygun şeyleri yapmamızı söyleyecektir. Bize sadakat ve şükranlarımı hak edecek şeyleri yapmamızı söyleyecek ve şüphesiz yapacağız. Sonuç olarak, eylemlerimiz ve hayatlarımız hükümetin düzenleyebileceği şekilde düzenlenecektir. Bu, anayasaların en mükemmelidir. ${ }^{12}$

\footnotetext{
12 Thomas Carlyle, On Heroes, Hero-Worship, and the Heroic in History (London: Chapman \& Hall, 1840), s.233-234. 'We come now to the last form of Heroism; that which we call Kingship. The Commander over Men; he to whose will our wills are to be subordinated, and loyally surrender themselves, and find their welfare in doing so, may be reckoned the most important of Great Men. he is practically the summary for us of all the various figures of Heroism; Priest, Teacher, whatsoever of earthly or spiritual dignity we can fancy to reside in a man embodies itself here, to command over us, to furnish us with constant practical teaching, to tell us for the day and hour what we are to do. He is called Rex, Regulator, Roi: our own name is still better; King, Könning,
} 
which means Can-ning, Able-man. Numerous considerations, pointing towards deep, questionable, and unfathomable regions, present themselves here: on the most part of which we must resolutely for the present forbear to speak at all. As Burke said that perhaps fair Trial by Jury was the soul of Government, and that all legislation, administration, parliamentary debating, and the rest of it, went on, in 'order to bring twelve impartial men into a jury-box'; - so, by much stronger reason, may I say here, that the finding of your Ableman and getting him invested with symbols of ability, with dignity, worship (worth-ship), royalty, knighthood, or whatever we call it, so that he may actually have room to guide according to his faculty of doing it, - is the business, well or ill accomplished, of all social procedure whatsoever in this world! Hustings-speeches, Parliamentary motions, Reform Bills, French Revolutions, all mean at hear this; or else nothing. Find in any country the Ablest Man that exists there; raise him to the supreme place, and loyally reverence him: you have a perfect government for that country; no ballot-box, parliamentary eloquence, voting, constitution-building, or other machinery whatsoever can improve it a whit. It is in the perfect state; an ideal country. The Ablest Man; he means also the truesthearted, justest, the Noblest Man: what he tells us to do must be precisely the wisest, fittest, that we could anywhere or anyhow learn; - the thing which it will in all ways behove us, with right loyal thankfulness, and nothing doubting, to do! Our doing and life were then, so far as government could regulate it, well regulated; that were the ideal of constitutions. 